\title{
confluências
}

\section{A AGENDA 2030 PARA O DESENVOLVIMENTO SUSTENTÁVEL DA ONU E SEUS ATORES: o impacto do desenvolvimento sustentável nas relações internacionais.}

Francisco Toniolo de Carvalho

Universidade Federal do Estado do Rio de Janeiro (UNIRIO)

\begin{abstract}
RESUMO
O presente artigo visa analisar o papel dos atores locais nas relações internacionais dentro do contexto de concretização dos 17 objetivos elencados na "Agenda 2030 para o desenvolvimento sustentável da Organização das Nações Unidas (ONU)", arrolados ao longo de um documento formal ratificado pelos seus 193 estados membros. Para isso, apresenta-se um breve histórico da construção do conceito de desenvolvimento sustentável bem como uma análise da evolução teórica sobre atores nas relações internacionais, com o objetivo de evidenciar qual função as cidades concretizam por serem o local onde será implementada a Agenda 2030. A metodologia utilizada enfatizou a revisão bibliográfica e a análise documental. A conclusão mostra que o documento pesquisado eleva o papel das cidades como atores internacionais.
\end{abstract}

Palavras-chave: Relações internacionais; Atores; Agenda 2030.

\section{THE UN 2030 AGENDA FOR SUSTAINABLE DEVELOPMENT AND ITS ACTORS: the impact of sustainable development on the International Relations.}

\begin{abstract}
This article aims to present the role of local actors in international relations within the context of achieving the 17 goals of the "2030 Agenda for sustainable development, of the United Nations (UN)", listed alongside a formal document ratified by its 193 states members. Persuing this purpose, we present a brief history on the construction of the sustainable development concept as well as an analysis of the theoretical evolution of international relations player/actors, intending to highlight which function the cities fulfill - as they are where the 2030 Agenda will be implemented. The methodology used emphasized literature review and document analysis. We conclude that the document researched improved the role of cities as an international actor.
\end{abstract}

Keywords: International relations; Players; 2030 agenda. 


\section{INTRODUÇÃO}

O desenvolvimento sustentável é assunto que atravessa anos de embates e discussões. Trata-se de uma consequência da exploração predatória dos recursos naturais do planeta, que remonta o século XVIII. Em razão disso, passou a ser debatido periodicamente em conferências realizadas pela ONU. Estas conferências buscam regular a cooperação internacional para manutenção de um planeta saudável para as futuras gerações. Em 2015 foi firmada entre os 193 estados membros da ONU a "Agenda 2030 para o desenvolvimento sustentável", com foco na cooperação para o seu alcance. Ela elenca 17 objetivos e 169 metas, outorgando uma maior importância e foco ao âmbito local (o das cidades) - onde os reflexos negativos da insustentabilidade são sentidos e as ações concretas devem ser adotadas.

A Agenda 2030 trata-se de documento ratificado por estados soberanos, mas prevê a implantação de ações e políticas concretas através de atores domésticos no cenário interno. Neste contexto, quais seriam os atores internacionais elencados pela Agenda 2030? Este documento apenas eleva a relevância internacional dos atores locais ou os insere nas relações internacionais? Este artigo pretende analisar a Agenda 2030 para o desenvolvimento sustentável buscando destacar quem são os atores que ela elenca, de acordo com algumas das principais teorias acerca das relações internacionais. Busca-se com isso mostrar qual o papel concedido aos atores domésticos na Agenda 2030, um documento firmado por estados soberanos - considerados os principais atores nas relações internacionais. Com isso, procuraremos apresentar a relevância outorgada aos atores locais através da atribuição que lhes foi alcançada pela Agenda 2030 de concretizarem os 17 objetivos para o desenvolvimento sustentável.

O artigo encontra-se estruturado da seguinte forma: sua primeira parte apresentará brevemente a história do desenvolvimento sustentável e dos tratados e acordos internacionais sobre o tema. A segunda parte analisa os atores em algumas das teorias clássicas e contemporâneas das relações internacionais. A terceira parte faz uma análise da Agenda 2030 e seus atores, verificando se eles são representados e considerados nível internacional. Ao final, nas conclusões, apresenta-se o entendimento advindo do estudo realizado e demonstra-se que a implementação de uma agenda internacional com foco no desenvolvimento sustentável dá suporte para o incremento do papel das cidades, atualmente apenas consideradas em âmbito local e não internacional, como participantes das relações internacionais. 


\section{EVOLUÇÃO HISTÓRICA DA AGENDA 2030: ESTUDANDO O DESENVOLVIMENTO SUSTENTÁVEL}

O caminho desenvolvimentista escolhido pela civilização é uma via de mão única em direção ao esgotamento das fontes de matéria prima. Foi com a "Revolução industrial", iniciada pelo Reino Unido no século XVIII, que o modelo de produção baseado na utilização de matérias primas não renováveis teve seu apogeu, sendo a forma de produção utilizada durante quase três séculos. A natureza foi tratada como subalterna ao homem, servindo-lhe como meios para atingir seus fins maiores inaugurados pela era do capitalismo: os lucros (CORRÊA, 2006: 93).

Após a segunda guerra mundial, iniciou-se uma discussão acerca de um novo conceito de desenvolvimento que não abrangesse apenas questões de crescimento econômico, mas também de bem-estar social, ambiental e político. Sachs (in MATOS e ROVELA, 2010: 3) aduz que as primeiras gerações de economistas desenvolvimentistas se inspiraram na cultura dominante na época de priorizar o pleno emprego, o "Estado de bem-estar social", o planejamento e intervenção econômicos para correção das falhas sociais do mercado.

$\mathrm{Na}$ virada da década de 70 a discussão acerca da necessidade de preservação dos recursos ambientais ganhou força. Foi na conferência das Nações Unidas sobre o "Ambiente humano", em 1972, que se concluiu sobre a necessidade de uma nova conceituação de desenvolvimento na qual inúmeras questões de alta complexidade deveriam estar envolvidas (NOVAES, 2003: 323). Essa tarefa foi delegada a uma comissão, presidida por Gro Brundtland, que em 1987 elaborou e publicou o relatório "Nosso futuro comum", documento que visou, entre outros temas, conceituar um novo modelo de desenvolvimento, o "desenvolvimento sustentável”. Segundo Novaes (2003, p. 324), esse era um documento:

[...] que já apontava para a grande questão da humanidade hoje - reconhecer que o planeta é finito, não tem recursos infindáveis; por isso, a humanidade precisa adotar formatos de viver - padrões de produção e consumo - sustentáveis, que não consumam mais recursos do que a biosfera terrestre é capaz de repor; não comprometam o meio ambiente, os muitos biomas do planeta, os seres que neles vivem, as cadeias alimentares e reprodutivas; não degradem os seres humanos; além disso, os padrões de viver não poderiam sacrificar recursos e comprometer os direitos das futuras gerações.

O relatório "Nosso futuro comum" conceituou desenvolvimento sustentável como um "conjunto de processos e atitudes que atende às necessidades presentes sem comprometer a possibilidade de que as gerações futuras satisfaçam suas próprias necessidades” (ONU, 1991: 46). O principal elemento desta definição é a interdependência entre a conciliação dos direitos dos 
presentes e das futuras gerações ao desenvolvimento socioeconômico e à proteção ao meio ambiente (FRIAS, 2011: 373).

A partir da década de 90 o conceito de desenvolvimento sustentável tornou-se um estandarte das políticas ambientais, voltado para a regularização de normas de padrões de produção, consumo, e qualidade dos produtos (CANELAS, 2004). O primeiro autor a tentar defini-lo foi Dudley Seers, no período logo após a segunda guerra mundial, embasando-se não só no crescimento econômico, mas também na condição humana de um país. Posteriormente, em 1995, os economistas Mahbub Ul Haq e Amartya Sen elaboraram o Índice de desenvolvimento humano (IDH), voltado para análise das condições sociais dos estados, contrapondo-se ao Produto interno bruto - PIB (MATOS e ROVELLA, 2010: 4).

Vinte anos após o início da longa trajetória em busca do desenvolvimento sustentável uma nova conferência da ONU foi realizada. Foi em 1992 na cidade do Rio de Janeiro, conhecida como “Cúpula da Terra”, "Eco92” ou "Rio92. Nela elaborou-se a "Agenda 21”, programa que estabeleceu ações para que os governos participantes abandonassem o crescimento econômico insustentável adotado até o momento, focando-se em modelos carreados pela sustentabilidade. Cinco anos depois (1997) uma nova "Cúpula da Terra" viria a ser realizada para revisar e avaliar o andamento da Agenda $21^{1}$.

Após a realização da Rio92, a ONU (em 1995), através de seu presidente geral Boutros Boutros-Ghali, publicou o documento "An agenda for development", ressaltando cinco dimensões para o desenvolvimento, que assim são descritas por Boisier (in MATOS e ROVELLA, 2010: 4):

1) Paz como pilar: A aproximação tradicional ao desenvolvimento pressupõe que este ocorre sob circunstâncias da paz. O desenvolvimento não pode prosseguir facilmente em sociedades onde os interesses militares estão no centro da vida;

2) A economia como o motor do progresso: O crescimento econômico é o motor do desenvolvimento. Acelerar a taxa do crescimento econômico é uma condição para expandir a base de recursos econômicos, tecnológicos e de transformação social não é suficiente, entretanto, perseguir o crescimento econômico por si só;

3) O ambiente como uma base para a sustentabilidade. O desenvolvimento e o ambiente não são conceitos separados, nem pode haver sucesso em um, sem que o mesmo ocorre com o outro;

4) Justiça como um pilar da sociedade: O desenvolvimento não ocorre em um vácuo, nem é construído em cima de uma fundação abstrata. O desenvolvimento ocorre dentro de um contexto social específico e em resposta às circunstâncias sociais específicas... O povo é o principal recurso de um país e seu bem-estar define o desenvolvimento;

5) Democracia na governança: A ligação entre o desenvolvimento e a democracia é intuitiva, por isso seu reflexo é difícil de elucidar. No contexto do desenvolvimento, a boa governança tem diversos reflexos. Entre seus projetos deve estar a perseguição de uma estratégia nacional voltada para o desenvolvimento. Projetos que assegurem a capacidade, a confiabilidade e a integridade das instituições do núcleo do estado moderno.

\footnotetext{
${ }^{1}$ Conforme histórico "A ONU e o meio ambiente". Disponível em: < https://nacoesunidas.org/acao/meio-ambiente/>. Acesso em: 19 jun. 2018.
} 
É a partir deste momento que o desenvolvimento se concretiza como conceito dotado de dimensões política, social e ambiental, se tornando complexo e de difícil concretização. Com base nessa nova conceituação, nota-se que atualmente é possível se atingir crescimento econômico, havendo criação de riqueza, sem necessariamente garantir-se uma real distribuição de renda e melhoria na qualidade de vida da população em geral (BOISIER in MATOS e ROVELLA, 2010: $5)$.

Ao longo dos anos novas conferências sobre a temática do desenvolvimento sustentável foram realizadas, destacando-se as seguintes: a segunda conferência da ONU sobre assentamentos humanos (1999), a sessão especial da assembleia geral sobre pequenos estados insulares em desenvolvimento (1999), a "Cúpula do milênio" e seus objetivos de "Desenvolvimento do milênio" (2000), a Rio+10 (Joanesburgo, 2002), a "Reunião mundial” (2005) e a Rio+20 (2012), na qual se reavaliou e repensou o desenvolvimento mundial e elaborou-se o documento " $O$ futuro que queremos" (no qual se busca concretizar o desenvolvimento sustentável no cenário global). Recentemente, na cidade de Nova Iorque, as questões acerca do desenvolvimento sustentável foram novamente discutidas, quando ocorreu a "Cúpula de desenvolvimento sustentável”, que culminou na adoção da "Agenda 2030 para o desenvolvimento sustentável” (2015) ${ }^{2}$.

A Agenda 2030 trata-se de um plano de ações debatido internacionalmente pelos estados com o foco de concretizar 17 objetivos e 169 metas voltados para efetividade do desenvolvimento sustentável econômico, social e ambiental ao longo do período 2016-2030 (ONU BR, 2015). Ela é o resultado de inúmeras negociações dos Estados-membros da ONU, e tem como signatários todos os 193 países pertencentes à organização. No Brasil, foi criado um grupo de trabalho interministerial para concretizar seus objetivos e metas, que envolve o poder executivo federal, estados, municípios, sociedade civil, movimentos sociais, setor privado e academia (MRE, 2016).

Os 17 objetivos que a agenda busca consolidar são (MRE, 2016):

Objetivo 1: Acabar com a pobreza em todas suas formas, em todos os lugares;

Objetivo 2: Acabar com a fome, alcançar a segurança alimentar e a melhoria da nutrição e promover a agricultura sustentável;

Objetivo 3: Assegurar uma vida saudável e promover o bem-estar para todos, em toda as idades;

Objetivo 4: Assegurar a educação inclusiva e equitativa de qualidade, e promover oportunidades de aprendizagem ao longo da vida para todos;

Objetivo 5: Alcançar a igualdade de gênero e empoderamento de todas as mulheres e meninas;

Objetivo 6: Assegurar a disponibilidade e gestão sustentável da água e o saneamento para todos;

Objetivo 7: Assegurar a todos o acesso confiável, sustentável, moderno e a preço acessível à energia;

\footnotetext{
${ }^{2}$ Conforme histórico "A ONU e o meio ambiente". Disponível em: < https://nacoesunidas.org/acao/meio-ambiente/>. Acesso em 19 jun. 2018.
} 
Objetivo 8: Promover o crescimento econômico sustentado, inclusivo e sustentável, emprego pleno e produtivo e trabalho decente para todos;

Objetivo 9: Construir infraestruturas resilientes, promover a industrialização inclusiva e sustentável e fomentar a inovação;

Objetivo 10: Reduzir a desigualdade dentro dos países e entre eles;

Objetivo 11: Tornar as cidades e os assentamentos humanos inclusivos, seguros, resilientes e sustentáveis;

Objetivo 12: Assegurar padrões de produção e de consumo sustentável;

Objetivo 13: Tomar medidas urgentes para combater a mudança do clima e os seus impactos;

Objetivo 14: Conservar e usar sustentavelmente os oceanos, os mares e os recursos marinhos para o desenvolvimento sustentável;

Objetivo 15: Proteger, recuperar e promover o uso sustentável dos ecossistemas terrestres, gerir de forma sustentável as florestas, combater a desertificação, deter e reverter a degradação da terra e deter a perda de biodiversidade;

Objetivo 16: Promover sociedades pacíficas e inclusivas para o desenvolvimento sustentável, proporcionar o acesso à justiça para todos e construir instituições eficazes, responsáveis e inclusivas em todos os níveis;

Objetivo 17: Fortalecer os meios de implementação e revitalizar a parceria global para o desenvolvimento sustentável.

Observa-se nos objetivos transcritos, bem como nas metas estabelecidas pelo documento analisado, inúmeras repetições da expressão "para todos". É necessário definir quem são "todos" no cenário de desenvolvimento sustentável internacional, qual seu peso e sua importância.

\section{OS ATORES INTERNACIONAIS: DEBATES TEÓRICOS ESSÊNCIAS}

As relações internacionais tratam-se de uma criação histórica, que surge da análise da existência e relações entre Estados no cenário global ao longo do tempo. Em sua história, desenvolveram-se teorias para explicar as relações no mundo em que vivemos, alternando entre diversas visões de atores no cenário internacional, de acordo com as relações dominantes em cada época e contexto. Esther Barbé leciona que "la condición de actor está ligada a necesidades concretas y temporales (evolución de la agenda internacional)"- (BARBÉ, 2001: 117), destacando que esta temporalidade influencia diretamente em quem será considerado ator nessas relações.

O prelúdio da disciplina das relações internacionais ocorreu com o surgimento da teoria realista, que recebeu esta designação por analisar tais relações de acordo com sua estrutura na realidade mundial, ou seja: as relações no mundo como ele é, em oposição à ideia de "dever ser" no cenário mundial (KAHLER, 1997: 26). Nogueira e Messari (2005: 21-24) apresentam como principais conceitos utilizados pelo realismo as ideias de centralidade dos estados, poder, autoajuda e estado de natureza. Os teóricos realistas apresentam um cenário mundial de anarquia, no qual não existe uma autoridade legítima e soberana conferida de poder de coerção para regular as relações entre estados e que garanta o direito à sobrevivência de todos os atores internacionais, onde impera o medo de não sobrevivência. 
Os atores internacionais desta teoria são os estados, que buscam maximizar seu poder e segurança. Em decorrência desta existência de um único tipo de ator no cenário internacional há uma rígida distinção entre esfera doméstica e internacional. Na primeira o progresso, a ordem e a paz são possíveis, mas são indiferentes e não operam na esfera internacional. Na segunda impera a anarquia e a desordem, sendo a guerra um pressuposto básico. Portanto, o poder é o aspecto central da teoria, e a insegurança internacional dificulta a cooperação (HERZ, 2015). No caso, tanto os indivíduos (políticos, diplomatas, burocratas, militares) como os grupos de indivíduos (burocracias e administrações públicas, entidades políticas, trabalhistas ou empresarias) não seriam atores no campo das relações internacionais, pois quando agem estão atuando em prol dos estados. Analisamse as relações entre estados, os atores unos e centrais, com função precípua de manutenção da segurança - seja interna ou externa - dos seus cidadãos. As relações domésticas são descartadas construindo o conceito de "estado como caixa preta" - pois seu âmbito interno não influencia as relações demais estados (NOGUEIRA e MESSARI, 2005: 24-25).

A crescente interdependência das sociedades pós Segunda Guerra Mundial faz com que os teóricos questionem as premissas do realismo. O pensamento liberal, que adota os pressupostos da racionalidade como característica da humanidade e da crença no progresso, indica que é possível transcender a política de poder e o caráter endêmico da guerra. O liberalismo dá ênfase a uma grande variedade de associações com diferentes escolas de pensamentos (como direito, economia e política), trazendo uma ampla gama de proposições sobre a natureza das relações internacionais (HERZ, 2015). Trata-se, na verdade, de uma teoria holística, que engloba diversas áreas do conhecimento. Ela estuda o local do indivíduo na sociedade e sua liberdade, analisando desde a economia até o lugar do estado na sociedade internacional. É uma tradição de pensamento focada no indivíduo, preocupando-se na sua relação com a sociedade e o governo em âmbito doméstico. Temos, neste momento, uma diminuição da força estatal, o qual passa a ser visto como um mal necessário e ameaça potencial. Enquanto necessário para a segurança interna e externa, passa a ser visto com desconfiança pelo possível abuso de poder, que pode ser exercido tiranicamente dentro de suas fronteiras, e buscando de forma exagerada externamente, causando a guerra (NOGUEIRA e MESSARI, 2005: 58-60).

Os liberalistas introduzem três grandes conceitos que vêm alterar a perspectiva da anarquia internacional realista, iniciando a inserção de outros atores no contexto internacional que não apenas os estados. São eles: o livre comércio, a democracia e as instituições internacionais (NOGUEIRA e MESSARI, 2005: 62).

A realidade da política internacional seria análoga à realidade de mercado, na qual atores buscam maximizar utilidades em um contexto competitivo. O aumento do comércio internacional 
favoreceria a paz, os regimes democráticos ou republicanos propiciariam uma relação pacífica entre estados e a criação de instituições internacionais poderia transformar as relações entre os atores do sistema internacional (HERZ, 2015). O livre-comércio traz uma interdependência econômica entre estados, aumentando a reciprocidade nos seus relacionamentos, o que concretiza a paz pela junção de interesses comuns. O comércio internacional é inserido no contexto das relações internacionais como nova forma de interação entre estados que não apenas disputas pelo poder, e assim surgem novos atores no cenário mundial (como aqueles agentes que o praticam) que podem direta ou indiretamente influenciar sua rotina e concretização. A questão da interdependência ganha força com o avanço da tecnologia nas relações entre estados - sejam comerciais, culturais ou ideológicas, e cada vez mais os acontecimentos no âmago doméstico de um estado afetam diretamente os outro (NOGUEIRA e MESSARI, 2005: 62-63, 81).

Da democracia advém a ideia de que estados democráticos tendem a manter relações pacíficas entre si, o que refletiria nas relações internacionais concretizando a paz. Isso porque nas repúblicas, onde se pratica a democracia, as decisões levariam em conta os interesses coletivos, e iniciativas que colocassem em risco os cidadãos e seu patrimônio deveriam ser sujeitas a uma ampla discussão, dificilmente sendo aprovadas (gerando maior prudência no governo). Sociedades democráticas tenderiam a resolver seus conflitos por meio do direito internacional, e as similaridades de compromissos com instituições e regras entre estados fomentaria a interação estatal e reduziria a possibilidade de conflito armado. De tais premissas decorre a construção liberal de que a opinião pública é de suma importância na definição de uma política externa racional e moderada, pois ela baliza a atuação estatal em matérias relevantes. Por fim, uma opinião pública democrática amplamente difundida auxilia no cenário internacional por aumentar a confiança dos atores externos, visto que os estados tenderiam a ter uma visão clara e transparente da política doméstica dos demais (NOGUEIRA e MESSARI, 2005: 63-66). Logo, traz-se para o cenário internacional uma paz decorrente de decisões do âmbito doméstico, devido à forma republicana e democrática de governo, a qual considera os interesses de seus cidadãos.

As instituições internacionais surgem dentro de um contexto de redução de crises e conflitos. Tais instituições são pensadas inicialmente no âmbito do direito das nações, que buscava regulamentar relações entre estados soberanos, e entre indivíduos e estados, para a formação de uma sociedade internacional focada na cooperação, sendo oriundas da vontade de estabelecerem-se regras de convivência baseadas no consenso. As instituições internacionais - ou instâncias supranacionais - auxiliariam a criar ordem na anarquia, ou seja, uma estabilidade e pacificação na convivência entre estados (NOGUEIRA e MESSARI, 2005: 67-68). As organizações internacionais seriam uma das fontes de ordem e cooperação do sistema. A presença de instituições vem favorecer 
a cooperação mútua entre estados, estabelecendo regras, coordenando processos e acordos internacionais e garantindo a colaboração e ação coletiva. As negociações na esfera doméstica passam a ter reflexo no cenário internacional, e o processo de transnacionalização apresenta novos atores, como as empresas transnacionais, as organizações não governamentais de caráter internacional e as próprias organizações internacionais interestatais. Governo e grupos de interesses passam a tomar decisões que afetam a operação do estado em nível internacional. Esta percepção de que tais instituições poderiam mudar as relações entre estados é a grande virada de paradigma entre liberalismo e realismo (HERZ, 2015).

Ao longo de sua evolução as instituições passaram a assumir um papel central no campo das relações internacionais por tomarem decisões em matérias relevantes, como na "Corte Internacional de Arbitragem", na "Liga das Nações" e na ONU. Sua importância se constrói através da coordenação internacional que realizam, após a adesão de estados membros que nelas discutirão assuntos de interesses comuns, e respeitarão, dentro do campo de funcionamento e atuação da instituição, as decisões tomadas. Por estes motivos que elas passam a ser consideradas novos atores no âmbito internacional.

O liberalismo traz então novos atores, além dos estados, para o campo das relações internacionais: as instituições internacionais, as empresas transnacionais e a sociedade civil, inclusive o indivíduo (em muitos casos cabe a eles a tomada de decisão com maior relevância). Estes novos personagens atuam em uma relação de interdependência complexa, onde a tomada de decisão perpassa por processo que abrange a todos, pois os afeta direta ou indiretamente. O estado ainda se mantém como o ator de maior relevância, mas as instituições ganham um papel de destaque pela sua atuação de congregar estados e auxiliar na legitimação de uma ordem mundial (NOGUEIRA e MESSARI, 2005: 81-82, 95-98). Robert Keohane e Joseph Nye apresentam a ideia de "interdependência complexa" como um cenário de interação entre diversos atores dotado das seguintes características: múltiplos canais de conexão de sociedades; agenda de relações interestatais consistente de múltiplos interesses, não apenas organizados pela hierarquia de poder; a força militar não é utilizada pelos governos contra outros governos ou regiões (KEOHANE, 2000: 77-78).

Já o marxismo é uma teoria que parte de premissas sociais e econômicas, não se dedicando diretamente às relações internacionais. Todavia, sua contribuição foi de grande valia. Ao analisar a sociedade mundial sob as premissas do capitalismo, o marxismo traz ao cenário mundial como atores os estados, as classes sociais e as empresas capitalistas - multinacionais ou transnacionais. Eventuais conflitos no sistema internacional seriam decorrentes das lutas de classes - pedra fundamental de análise do mundo por esta teoria - entre burguesia e proletariado, e da expansão e 
desenvolvimento dos interesses capitalistas (NOGUEIRA e MESSARI, 2005: 108). A compreensão das instituições e do sistema internacional advém do capitalismo e do processo de acumulação global, da luta de classes e interesse das elites e das potências capitalistas em manter os sistemas de dominação de potências imperialistas e estados subdesenvolvidos. A dominação toma forma no conflito entre estados, encontrando-se também dentro dos mesmos. A anarquia proposta pelos realistas não é inerente do cenário internacional, mas é o resultado da produção capitalista e da dominação do imperialismo (HERZ, 2015).

As elites globalizantes assumem papel de relevância na estruturação da economia política global. Surgem então os conceitos de "hegemonia" e de "potência hegemônica", que envolvem coerção (poder) e consenso. Nesta teoria o consenso é importante, pois é através dele que as partes dominadas aceitam a dominação. Ele é construído pelos dominantes, e replicado através da sociedade civil, envolvendo temas cruciais. Este consenso passa a ser aceito pelas partes dominadas, afetando diretamente suas aspirações, interesses econômicos e particulares, sendo útil para uma manutenção de "status quo" pelas potências capitalistas (HERZ, 2015).

Esta teoria destaca como pontos políticos internacionais fundamentais a organização das classes trabalhadoras para conquista do poder político, a solidariedade nas suas lutas e inserção na política, demonstrando a inclusão do proletariado no rol de atores internacionais. A burguesia já fazia parte deste cenário mundial, pois o capital encontrava-se em todos os lugares, através das empresas multinacionais. Esta expansão do capital monopolista - denominada imperialismo causaria a internacionalização das relações sociais, de modos de produção capitalista e da luta de classes (NOGUEIRA e MESSARI, 2005: 108-109, 114-115). Na teoria marxista as organizações internacionais ganham destaque no seu papel de reforçar a manutenção do modo de produção e exploração capitalista (HERZ, 2015).

Por fim, a "Teoria Crítica" analisa profundamente o neorrealismo. Extrapolando a relação estatal de poder, ela estuda a formação histórica do estado e traz para discussão questões antes esquecidas ou consideradas coadjuvantes, como a hegemonia, a emancipação, a desigualdade, o meio ambiente, a centralidade dos estados nas relações internacionais, a integração econômica e política mundial, a ética, a sociedade civil global, e outros temas relevantes. Os atores internacionais seriam aqueles que estão dentro do estado e influenciam sua tomada de decisão política. A apreciação realizada recai sobre todas as questões investigadas nos campos internacionais, fazendo com que os atores surjam constantemente, de acordo com o tema analisado, e da tomada de decisão (por exemplo: imigrantes, mercado de trabalho, questões sociais e econômicas, questões ambientais, etc.). Esta teoria utiliza-se em parte do marxismo para sua construção, reformulando dois pontos que lhe são fundamentais: o primeiro é o reconhecimento de 
que a razão é limitada ante as relações sociais complexas e é necessário criticar-se as limitações das teorias da sociedade; o segundo trata da importância dos processos de aprendizado e produção de conhecimento para análise dos conflitos e contradições sociais. A teoria percebe as relações internacionais não apenas como a relação entre estados, mas sim como uma consequência das relações da sociedade civil, ampliando a análise internacional - que passa a englobar a ação transnacional de parcela da sociedade civil que possui força para atuar no cenário internacional (NOGUEIRA e MESSARI, 2005: 132-133, 136, 147).

A "Teoria crítica" realiza uma profunda análise das bases das relações construindo suas premissas e seus estudos através do marxismo, mas também de novos temas e os novos debates para além do capitalismo, da luta de classes, da dominação e do local dos estados em uma ordem internacional imperialista. Observa-se que a gama de atores internacionais se amplia, e as instituições voltam a ser importantes. A forte crítica realizada ao neorrealismo questiona o papel do estado nas relações internacionais e traz à tona estes novos atores, frutos de uma crítica à construção do estado. Estes não são apenas atores estáticos, mas dinâmicos, pois fazem parte da evolução e do processo histórico formador de uma realidade política estatal decorrente de interações humanas e sociais (NOGUEIRA e MESSARI, 2005: 150-151).

\section{AGENDA 2030: TEORIAS E ATORES CONTEMPORÂNEOS}

As teorias clássicas das relações internacionais reconheciam como atores apenas os estados soberanos, posto que, em um contexto anárquico, somente eles possuíam poder para interação. Esta situação não mais perdura. A evolução histórica da disciplina nos apresenta um crescimento do número de atores e aumento da relevância do papel das organizações internacionais ao longo de toda sua história, em virtude da realidade complexa do cenário global. Seja organizando a anarquia, seja organizando a cooperação entre atores para vantagens mútuas e minimização de conflitos (BARBÉ, 2001: 167), elas vêm ampliando sua importância, especialmente pelo processo de ordenação global - do qual se tornam o marco representativo (CLAUDE in BARBÉ, 2001: 151). Tais organizações possuem características que as distinguem dos demais atores internacionais contemporâneos: caráter interestatal, base voluntária, órgãos permanentes, vontade autônoma, competências próprias e cooperação entre os membros para satisfação de interesses comuns (RIDRUEJO in BARBÉ, 2001: 153). Seu caráter global aumentou a interdependência estatal, e auxiliou os países centrais - as chamadas "potências" - a melhorar seus níveis de bem-estar e segurança. Com relação aos países periféricos, a proliferação destas organizações auxiliou-os no desenvolvimento da paz e do bem-estar (BARBÉ, 2001: 170). 
No momento atual, a maior das organizações internacionais em termos de participação é a ONU, da qual fazem parte 193 países. Dentro desta organização foi formalizada a Agenda 2030 para o desenvolvimento sustentável, ratificada por todos os seus estados membros. Tal agenda prevê a colaboração entre distintos atores para a implantação de seus objetivos e metas. São eles: os governos, a academia, o setor empresarial, os cidadãos e a sociedade civil (ONU-BR, 2015). Tratase de uma "agenda do povo, pelo povo e para o povo" (MRE, 2016).

A qualidade de ator no cenário internacional decorre da natureza da unidade analisada, e de sua capacidade e habilidade em cumprir as funções e objetivos que lhe são propostos dentro do sistema internacional, possuindo capacidade de mobilizar recursos e exercer influência sobre outros atores no sistema, e gozando de certa autonomia. Portanto, são condições para ser ator internacional: capacidade, habilidade e autonomia. Um ator internacional possui três características: realiza atividades continuadas e significativas, de impacto contínuo no sistema; é levado em consideração pelos elaboradores de política exterior e tem impacto na sua formação; tem autonomia e liberdade na tomada de decisão (BARBÉ, 2001: 117-118).

Toda autoridade, todo organismo, todo grupo e toda pessoa capaz de influenciar o cenário internacional será qualificada como ator internacional. Marcel Merle (in BARBÉ, 2001: 119) considera que existem três tipos de atores: os estados, as organizações interestatais ou intergovernamentais e as forças transnacionais, desde que preencham os requisitos para serem atores. Esther Barbé (2001: 121) considera como atores internacionais: Estados, organizações intergovernamentais - denominadas por ela como organizações internacionais - e forças transnacionais. Já Richard Mansbach (in BARBÉ, 2001: 120) apresenta seis atores, três públicos e três privados: atores governamentais interestatais (ex.: Organização dos Estados Americanos OEA), atores não governamentais interestatais (ex.: multinacionais, atores que realizam atividade internacional, mas não representam governos), estados, atores governamentais não centrais (governos locais, municípios e estados), atores interestatais não governamentais (Ex.: partidos políticos, organizações filantrópicas, que tenham relações com atores internacionais, mas à margem do governo) e indivíduo (com influência internacional).

Analisando criticamente os atores elencados pela Agenda 2030, de acordo com as matrizes teóricas da disciplina, podemos observar que, em virtude da realidade mundial complexa atual, o documento optou por incluir o maior número de participantes na concretização dos seus objetivos. Ele traz para o momento de implantação dos objetivos de uma agenda internacional, ratificada por estados, outras categorias de atores não-estatais, inclusive o próprio indivíduo, em virtude de se tratar de um documento que prevê medidas que serão concretamente realizadas no âmbito local. Todos estes atores colaboram entre si, pois materializam parte dos objetivos e metas traçados pela 
agenda. É através da sua atuação sua conjunta que se alcançará o desenvolvimento sustentável internacional, elevando-os para além do cenário local.

Tal situação é de suma importância. Conforme verificado, o surgimento histórico do desenvolvimento sustentável é o reflexo de inúmeros anos de descaso com as condições ambientais globais. O estudo e evolução das teorias acerca do conceito mostram-nos que os estados devem tomar a liderança elaborando políticas públicas e programas de governo que sigam na busca da concretização do desenvolvimento sustentável, mas é no âmbito local - o das cidades - que os reflexos da insustentabilidade são sentidos, e onde as ações concretas devem ser adotadas. A sua não implantação afetará diretamente os cidadãos no seu local de vida. Portanto, trazer para a Agenda 2030 atores de âmbito regional e local é dar força e voz nas relações internacionais para os maiores afetados pela degradação social e ambiental decorrente das atuais formas de produção e pujança econômica. Permite-se assim que os maiores afetados por este processo de degradação possam participar das escolhas e auxiliar a definir quais macro políticas serão escolhidas - situação até então inexistente. Ainda, é uma forma de outorga-lhes direito de participar da implantação das políticas focadas no alcance do desenvolvimento sustentável, conferindo força para atores que muitas vezes são relegados pelas relações internacionais.

\section{CONSIDERAÇÕES FINAIS:}

Cada vez mais o número de atores cresce no cenário internacional, evoluindo da situação de anarquia estatal e atores unitários para um cenário de atores múltiplos e complexos, o qual interrelaciona inúmeras figuras que convivem em um mesmo espaço, buscando objetivos distintos, mas nem sempre conflitantes (muitas vezes em cooperação). Para auxiliar na coordenação de toda esta vasta gama de relações interdependentes surgem organizações internacionais, que auxiliam na ordem global, sendo a ONU a de maior importância na atualidade, a qual conta com a participação de todos os estados.

O fato dos atores dividirem o mesmo espaço comum fez crescer e se destacar, ao longo do tempo, a necessidade de regulamentação do desenvolvimento das nações. O meio ambiente global deve ser preservado para o bem de todos, e utilizado sem abuso pelas maiores potências. Na verdade, tais potências deveriam sofrer maiores restrições, por questões históricas de exploração predatória dos recursos naturais e degradação planetária. Esta é a razão de, ao longo dos anos, inúmeros acordos e tratados submeterem os estados a regras que buscam concretizar o desenvolvimento sustentável, limitar a insustentabilidade atual e regular os pesos nesta balança desigual - onde encontramos uma enorme discrepância entre os estados envolvidos. 
A Agenda 2030 - ratificada por estados dentro de uma organização internacional apresenta como os atores domésticos irão implementar ações, e traz o âmbito local para o campo das relações internacionais. Assim, concede-lhes relevância na aplicação e concretização de seus objetivos, especialmente por focar nele as políticas de desenvolvimento sustentável.

O debate acerca do desenvolvimento sustentável se iniciou na década de 1960, e seguirá sempre como um tema relevante. A adjetivação do desenvolvimento das nações como sendo sustentável precisa acompanhar as mudanças constantes inerentes a uma civilização tecnológica. Além disso, deve sempre apresentar metas desafiadoras aos estados, mantendo seu foco na melhoria contínua e na busca da melhor condição possível aos habitantes do planeta, implicando em benefícios e sacrifícios. Tais situações apresentam-nos um cenário onde será difícil concretizar as ideias de desenvolvimento sustentável. Todavia, observa-se que as teorias sobre as relações internacionais e desenvolvimento sustentável acompanham a evolução global, buscando estar atualizadas e em consonância com o cenário que refletem, para servirem aos seus propósitos de melhoria da qualidade de vida global.

\section{REFERÊNCIAS:}

BARBÉ, Esther. Relaciones internacionales. 2. ed. Madrid: Tecnos, 2001.

CANELAS, André. A evolução do conceito de desenvolvimento sustentável e as suas interações com as políticas econômica, energética e ambiental. 2004. Disponível em: $<$ http://www.portalabpg.org.br/PDPetro/3/trabalhos/IBP0111_05.pdf \. Acesso em: 11 jun. 2018.

CORREAA, Darcísio; BACKES, Elton Gilberto. Desenvolvimento sustentável: em busca de novos fundamentos. In: SPAREMBERGER, Raquel Fabiana Lopes; PAVIANI, Jayme. Direito ambiental: um olhar para a cidadania e sustentabilidade planetária. Caxias do Sul: Educs, 2006. p. 83-114.

FRIAS, Juliana Moraes. A relação entre equidade intergeracional e desenvolvimento sustentável. In: BEJAMIN, Antônio Herman et alia (orgs.). Congresso brasileiro de direito ambiental PNMA: 30 anos da Política Nacional de Meio Ambiente. São Paulo: Imprensa oficial do Estado de São Paulo, 2011. v. 1. p. 367-376.

HERZ, Mônica. Contribuições teóricas para o estudo das organizações internacionais. In: HERZ, Mônica e HOFFMAN, Andrea. Organizações internacionais: histórias e práticas. Rio de Janeiro: Elsevier, 2015. cap. 2. Ebook. Disponível em: <https://books.google.com.br/books?hl=pt$\mathrm{BR} \& 1 \mathrm{r}=\& \mathrm{id}=\mathrm{QZXpCgAAQBAJ} \& \mathrm{oi}=\mathrm{fnd} \& \mathrm{pg}=\mathrm{PT} 3 \& \mathrm{dq}=\mathrm{Contribui} \% \mathrm{C} 3 \% \mathrm{~A} 7 \% \mathrm{C} 3 \% \mathrm{~B} 5 \mathrm{es}+\mathrm{te} \% \mathrm{C} 3 \%$ B3ricas + para $+\mathrm{O}+$ estudo + das + organiza $\% \mathrm{C} 3 \% \mathrm{~A} 7 \% \mathrm{C} 3 \% \mathrm{~B} 5 \mathrm{es}+$ internacionais \&ots $=\mathrm{kz} 6 \mathrm{~m} 5 \mathrm{MAJMh} \&$ sig=ndpcx-qdEb0--$\mathrm{d} 2$ naazY1JDHVM $\# \mathrm{v}=$ onepage \&q=Contribui $\% \mathrm{C} 3 \% \mathrm{~A} 7 \% \mathrm{C} 3 \% \mathrm{~B} 5 \mathrm{es} \% 20 \mathrm{te} \% \mathrm{C3} \% \mathrm{~B} 3 \mathrm{ricas} \% 20 \mathrm{para} \%$ $20 \mathrm{o} \% 20$ estudo $\% 20$ das $\% 20$ organiza $\% \mathrm{C} 3 \% \mathrm{~A} 7 \% \mathrm{C} 3 \% \mathrm{~B} 5 \mathrm{es} \% 20$ internacionais\&f=false $>$. Acesso em: 11 jun. 2018. 
KAHLER, Miles. Inventing international relations: international relations theory after 1945. In: DOYLE, M. W. \& IKENBERRY, G. J. (eds). New Thinking in International Relations Theory. Boulder: Westview, 1997.

KEOHANE, Robert O. e NYE, Joseph. Realism and complex interdependence. In: LECHNER, Frank J. e BOLI, John. The globalization reader. Oxford (UK): Blackwell, 2000, p. 77-83.

MATOS, Richer de Andrade; ROVELLA, Syane Brandão Caribé. Do crescimento econômico ao desenvolvimento sustentável: conceitos em evolução. Revista eletrônica dos cursos de Administração e Ciências Contábeis - Faculdade Opet [online]. n. 3, jan./jul. 2010. Disponível

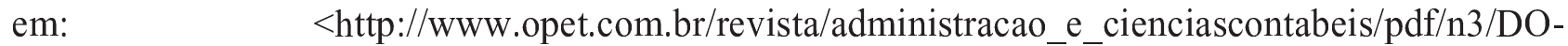
CRESCIMENTO-ECONOMICO-AO-DESENVOLVIMENTO-SUSTENTAVEL-CONCEITOSEM-EVOLUCAO.pdf>. Acesso em: 15 jun. 2018.

MRE. Ministério das Relações Exteriores. Agenda 2030 para o desenvolvimento sustentável. 2016. Disponível em: <http://www.itamaraty.gov.br/pt-BR/politica-externa/desenvolvimentosustentavel-e-meio-ambiente/135-agenda-de-desenvolvimento-pos-2015 $\geq$. Acesso em: 25 jun. 2018.

ONU. Organização das Nações Unidas. Comissão mundial sobre o meio ambiente e desenvolvimento. Nosso futuro comum. 2. ed. Rio de Janeiro: Fundação Getúlio Vargas, 1991.

ONU Brasil. Organização das Nações Unidas do Brasil. A Agenda 2030. 2015. Disponível em: $<$ https://nacoesunidas.org/pos2015/agenda2030/>. Acesso em: 21 jun. 2018.

NOGUEIRA, João Pontes; MESSARI, Nizar. Teoria das relações internacionais: correntes e debates. Rio de Janeiro: Elsevier, 2005.

NOVAES, Washington. Agenda 21: um modelo de civilização. In: TRIGUEIRO, André. Meio Ambiente no século 21. Rio de Janeiro: Sextante, 2003. p. 323-331.

\section{AUTOR:}

Francisco Toniolo de Carvalho

Mestrando em Direito na Universidade Federal do Estado do Rio de Janeiro (UNIRIO)

E-mail: adv.toniolodecarvalho@gmail.com

Recebido em 23/10/2018.

Aceito em 24/07/2019. 